\title{
Trends in Micronutrient Laboratory Testing in Switzerland: A 7-Year Retrospective Analysis of Healthcare Claims Data
}

This article was published in the following Dove Press journal: International Journal of General Medicine

\author{
Carola A Huber ${ }^{1,2}$ \\ Michael Nagler (D) $^{3}$ \\ Thomas Rosemann (iD) ${ }^{2}$ \\ Eva Blozik (D) ${ }^{1,2}$ \\ Markus Näpflin ' \\ Stefan Markun (iD) ${ }^{2}$ \\ 'Department of Health Sciences, Helsana \\ Insurance Group, Zürich, Switzerland; \\ ${ }^{2}$ Institute of Primary Care, University of \\ Zürich, University Hospital Zürich, \\ Zürich, Switzerland; ${ }^{3}$ University Institute \\ of Clinical Chemistry, Inselspital Bern \\ University Hospital, University of Bern, \\ Bern, Switzerland
}

Background: Micronutrient laboratory tests (MLT) are increasing in many healthcare systems. This study assessed time trends of annual MLT incidence in the Swiss population and examined the frequency of specific MLT, defined as the number of yearly tests performed in individual persons.

Methods: For annual time trends, we used a longitudinal design with a seven-year observation period (2012-2018) and for yearly testing frequency we used a cross-sectional design (2018 only). The database consisted of nationwide insurance claims from adult persons.

Results: Persons with MLT compared to persons without were older (mean age 57.1 years vs 48.6 years) and to a higher proportion female (65.1\% vs 45.5\%). Between 2012 and 2018, we included 6.7 million person years and found an increase in the proportion of persons receiving any MLT from $24.5 \%$ to $35.0 \%$. Tests with strongest absolute increase during the observation period were vitamin D (from $7.4 \%$ of persons to $20.4 \%$ ), vitamin B12 (from $9.0 \%$ to $17.6 \%$ ) and ferritin (from $17.4 \%$ to $26.6 \%$ ). In 2018, vitamin D and vitamin B12 tests were performed more than once in $4.5 \%$ and $3.3 \%$ of the population, respectively.

Conclusion: We found that the Swiss population undergoes MLT with high and increasing frequency. Testing for vitamin D, vitamin B12 and ferritin is very common and of questionable appropriateness.

Keywords: laboratory testing, micronutrient, claims data, trend

\section{Introduction}

Laboratory testing plays a key role in the treatment of patients and is essential for clinical decision-making. A high proportion of physicians' decisions rely on laboratory testing results in clinical practice. ${ }^{1}$ However, in the last decades, laboratory testing significantly increased in nearly all industrialized countries; as data from several countries such as Canada, UK, and Sweden reflect. Questions have been raised on whether all these tests were appropriate and had consequences for clinical decision-making. ${ }^{2-4}$ While increases in specific laboratory tests can be understood before the background of demographic changes, an increase in micronutrient laboratory testing (MLT) is difficult to understand especially in developed countries. However, studies on a comprehensive set of micronutrient tests are very scarce and only a few studies focusing on a specific micronutrient test such as vitamin D exist. ${ }^{3-6}$ For example, increased testing for vitamin $\mathrm{D}$ has been observed in several countries, and even though guidelines do not advocate or even discourage screening for vitamin D deficiency. ${ }^{5-10}$
Correspondence: Carola A Huber Department of Health Sciences, Helsana Insurance Group, P.O. Box, 808I, Zürich, Switzerland

Tel +4I 43340634 I

$\mathrm{Fax}+4 I 433400434$

Email carola.huber@helsana.ch
International Journal of General Medicine 2020:13 |34|-1348

I34 |

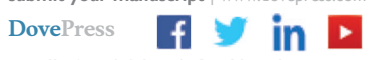

http://doi.org/10.21 14711GM.5275406 
In Switzerland, a recent database analysis found increasing MLT use in general practice but comprehensive population-based studies are still lacking. ${ }^{11}$ Such insights, however, are necessary to advance the understanding of potential overuse of MLT. Therefore, the aim of this study, was to assess population-based time trends, incidence and frequency of MLT in Switzerland.

\section{Methods}

\section{Design and Setting}

We performed a retrospective population-based study incorporating both a longitudinal and a cross-sectional design using electronic healthcare claims database from one of the largest health insurance companies in Switzerland (Helsana Group). The database contained nationwide data, including pharmacy, medical and health services records, from about 1.2 million mandatorily insured persons across all cantons ( $\sim 15 \%$ of the Swiss population). We considered all healthcare invoices submitted to Helsana Group for reimbursement and extracted, deidentified and anonymized persons' data from the Helsana data warehouse for analysis. As already shown in previous analysis, Helsana claims data are a representative sample from the Swiss general population. ${ }^{12,13}$ Every Swiss resident is obligated to be enrolled in a basic health insurance, which is provided by health insurers on private market, but regulated by federal authorities. The basic health insurance is obligated to offer basic health insurance to every Swiss resident and to guarantee medical treatment. We included anonymized claims data records from 2012 to 2018 containing information on sociodemographic characteristics and laboratory testing of mandatorily insured persons $\geq 18$ years of age. For the longitudinal design, we analyzed claims data per person and year (2012-2018), and for the cross-sectional design, we included claims data per person in the most recent year, 2018. The analyzed data of this study are available from the Helsana Group but restrictions exist for the availability of these data that were used under license for the current study. Data are therefore not publicly accessible but can be obtained from the authors by reasoned request and with permission from Helsana.

\section{Laboratory Tests}

A sample of MLT was selected from the list of analyses (AL) from the Federal Office of Public Health. ${ }^{14}$ The AL contains all laboratory tests covered by the mandatory health insurance in Switzerland. The selected laboratory tests were categorized into a vitamin domain (including vitamin $\mathrm{D}$, folic acid, homocysteine, methylmalonic acid, holotranscobalamin, vitamin B12/cyanocobalamin, and other vitamins), a mineral domain (including magnesium and calcium) and a trace elements domain (including iron, ferritin, transferrin, and other trace elements). A detailed list of included MLT and categories is shown in Supplementary Table S1. Tests were aggregated when they measured closely related metabolites (eg different forms of vitamin D).

\section{Objectives}

To determine trends in MLT by measuring absolute annual changes in proportions of persons receiving any or specific MLT during the total observation period (longitudinal design).

To determine incidence of specific MLT stratified by age groups.

To determine frequency of MLT by counting the number of MLTs ordered in individual persons in 2018 (crosssectional design).

\section{Statistical Analysis}

Using data from 2012 to 2018 (longitudinal), we assessed trends in MLT over seven years by calculating the incidence of laboratory testing per year as the proportions of persons receiving MLT (any, by domain and by individual test) in the total sample. Multiple tests of the same MLT were thereby considered as one test in this analysis. To calculate the absolute annual changes in testing for MLT over the years (2012-2018), a linear regression model was computed using year as continuous variable. Estimates were reported as coefficients including 95\% confidence intervals $(95 \%-\mathrm{CI})$. Statistical significance was set at the 0.05 level. In addition, we report relative changes over the total seven-year observation period, which were calculated by dividing the proportion of persons with the given test in 2012 by those with the test in 2018 .

To calculate incidence by age groups we used the data from 2018 exclusively (cross-sectional) and stratified the population in those aged 18-44, 45-64 and $\geq 65$.

To assess frequency of MLT in individual persons we also used data from 2018, counted the number of individual tests per person and reported proportions of persons receiving no test, one test, two tests, or more than two tests.

We report data using descriptive statistics and use group comparison tests. Categorical variables were presented as absolute numbers of persons and percentages, continuous data as mean value including standard deviation. The 
Pearson's chi-squared test was used to test categorical variables for independency. Differences regarding to continuous variables such as age (in years) were analyzed with a nonparametric analysis of variance (Kruskal-Wallis test for $>2$-groups-comparisons). Statistical significance was set at the 0.05 level. All analyses were performed using the statistical program R version 3.6.1 (R Development Core Team 2019).

\section{Results}

\section{Trends in MLT (Longitudinal)}

During the seven-year observation period, we included 6.7 million person years. Population sizes by year ranged between 906,230 (in 2017) and 997,761 (in 2012). In 2012, the proportion of persons receiving any MLT was $24.5 \%$ and the absolute annual change was $+1.8 \%(95 \% \mathrm{CI}=1.5 \%$ to $2.1 \%$; relative seven-year increase by a factor of 1.4$)$. We observed annual increases of proportions of persons receiving any MLT across all MLT domains, the strongest increase appeared in vitamin testing with $+2.2 \%(95 \% \mathrm{CI}=+2.0 \%$ to $+2.4 \%$; relative seven-year increase by a factor of 2.0 ). For trends in overall and domain specific MLT see Table 1.

We found statistically significant annual increases in percent of the population tested in every individual MLT (Table 2). The largest annual increases we found in proportions of persons tested for vitamin $\mathrm{D}(+2.2 \%$; $95 \% \mathrm{CI}$ $=2.0 \%$ to $2.5 \%)$, vitamin $\mathrm{B} 12(+1.5 \% ; 95 \% \mathrm{CI}=1.4 \%$ to $1.6 \%)$ and ferritin $(+1.5 \%$; $95 \% \mathrm{CI}=1.4 \%$ to $1.7 \%)$. Figures 1 and 2 show trends in MLT on the level of individual tests.

\section{Sociodemographic Characteristics} (Cross-Sectional)

From the year 2018, we included 934,685 adult persons, $52.4 \%$ women with mean age 51.5 years (SD 19.7; results not shown). Overall, about $35 \%$ of the persons had at least one MLT in 2018. Considerable differences appeared when comparing persons receiving micronutrient testing with those who did not: Patients with MLT were older (mean age 57.1 years vs 48.6 years), and to a higher proportion of female gender (65.1\% vs $45.5 \%$; Table 3$)$. Differences in language regions were small.

Concerning MLT by age groups, we found that persons $\geq 65$ years old had the highest testing incidence consistently across all specific MLT. The highest incidence in this group we noted in testing for ferritin (34.1\%), vitamin D (29.7\%) and vitamin B12 (26.8\%). Conversely, persons 18-44 years old had the lowest testing incidences, but the ranks in the distribution were similarly distributed with ferritin in first place (22.0\%), vitamin D second (13.2\%) and vitamin B12 third (11.3\%). Table 4 shows testing incidences in 2018 by age groups.

\section{Frequency of MLT}

Our data comprised 1.29 million MLT in 2018. Most frequently ordered MLT were ferritin (0.30 million), vitamin D (0.21 million) and vitamin B12 (0.18 million). In terms of testing frequency, ferritin was in first place being performed in $26.6 \%$ of persons (19.4\% performed once; $7.3 \%$ performed twice or more) followed by vitamin

Table I Proportions of Persons with MLT by Years 2012-2018

\begin{tabular}{|c|c|c|c|c|c|c|c|c|}
\hline \multirow[t]{3}{*}{ Variables } & \multicolumn{7}{|l|}{ Year } & \multirow{3}{*}{$\begin{array}{l}\text { Absolute Annual } \\
\text { Change }[95 \%-\mathrm{Cl}]\end{array}$} \\
\hline & 2012 & 2013 & 2014 & 2015 & 2016 & 2017 & 2018 & \\
\hline & $\mathbf{N}(\%)$ & $\mathbf{N}(\%)$ & $\mathbf{N}(\%)$ & $\mathbf{N}(\%)$ & $\mathbf{N}(\%)$ & $\mathbf{N}(\%)$ & $\mathbf{N}(\%)$ & \\
\hline Total & $\begin{array}{l}997,761 \\
(100.0 \%)\end{array}$ & $\begin{array}{l}988,564 \\
(100.0 \%)\end{array}$ & $\begin{array}{l}978,17 \mid \\
(100.0 \%)\end{array}$ & $\begin{array}{l}981,735 \\
(100.0 \%)\end{array}$ & $\begin{array}{l}956,119 \\
(100.0 \%)\end{array}$ & $\begin{array}{l}906,230 \\
(100.0 \%)\end{array}$ & $\begin{array}{l}934,685 \\
(100.0 \%)\end{array}$ & \\
\hline $\begin{array}{l}\text { Persons with } \geq I \text { test } \\
\text { for MLT }\end{array}$ & $\begin{array}{l}244,926 \\
(24.5 \%)\end{array}$ & $\begin{array}{l}265,719 \\
(26.9 \%)\end{array}$ & $\begin{array}{l}284,553 \\
(29.1 \%)\end{array}$ & $\begin{array}{l}300,770 \\
(30.6 \%)\end{array}$ & $\begin{array}{l}313,897 \\
(32.8 \%)\end{array}$ & $\begin{array}{l}311,166 \\
(34.3 \%)\end{array}$ & $\begin{array}{l}327,320 \\
(35.0 \%)\end{array}$ & $1.8 \%(1.5-2.1 \%)$ \\
\hline $\begin{array}{l}\text { Persons with } \geq 1 \\
\text { vitamin test }\end{array}$ & $\begin{array}{l}|34,93| \\
(\mid 3.5 \%)\end{array}$ & $\begin{array}{l}158,7 \mid 5 \\
(16.1 \%)\end{array}$ & $\begin{array}{l}180,220 \\
(18.4 \%)\end{array}$ & $\begin{array}{l}201,539 \\
(20.5 \%)\end{array}$ & $\begin{array}{l}221,974 \\
(23.2 \%)\end{array}$ & $\begin{array}{l}228,942 \\
(25.3 \%)\end{array}$ & $\begin{array}{l}246,820 \\
(26.4 \%)\end{array}$ & $2.2 \%(2.0-2.4 \%)$ \\
\hline $\begin{array}{l}\text { Persons with } \geq 1 \\
\text { mineral test }\end{array}$ & $\begin{array}{l}109,005 \\
(10.9 \%)\end{array}$ & $\begin{array}{l}|| 8,73 \mid \\
(12.0 \%)\end{array}$ & $\begin{array}{l}|29,60| \\
(13.2 \%)\end{array}$ & $\begin{array}{l}137,743 \\
(14.0 \%)\end{array}$ & $\begin{array}{l}145,4 \mid 0 \\
(15.2 \%)\end{array}$ & $\begin{array}{l}145,420 \\
(16.0 \%)\end{array}$ & $\begin{array}{l}153,393 \\
(16.4 \%)\end{array}$ & $1.0 \%(1.0-1.0 \%)$ \\
\hline $\begin{array}{l}\text { Persons with } \geq 1 \text { trace } \\
\text { element test }\end{array}$ & $\begin{array}{l}179,403 \\
(18.0 \%)\end{array}$ & $\begin{array}{l}195,912 \\
(19.8 \%)\end{array}$ & $\begin{array}{l}211,491 \\
(21.6 \%)\end{array}$ & $\begin{array}{l}226,085 \\
(23.0 \%)\end{array}$ & $\begin{array}{l}236,407 \\
(24.7 \%)\end{array}$ & $\begin{array}{l}235,578 \\
(26.0 \%)\end{array}$ & $\begin{array}{l}251,372 \\
(26.9 \%)\end{array}$ & $1.5 \%(1.3-1.7 \%)$ \\
\hline
\end{tabular}


Table 2 Temporal Changes of MLT

\begin{tabular}{|l|l|l|l|}
\hline Variables & Absolute Annual Change (95\%-CI) & Proportion of Persons Tested in 20 I2 & Relative Seven-Year Change \\
\hline Vitamin D & $+2.2 \%(2.0-2.5 \%)$ & $7.40 \%$ & 2.8 \\
Vitamin BI2 & $+1.5 \%(1.4-1.6 \%)$ & $9.00 \%$ & 2.0 \\
Ferritin & $+1.5 \%(1.4-1.7 \%)$ & $17.40 \%$ & 1.5 \\
Folic acid & $+1.0 \%(1.0-1.1 \%)$ & $5.40 \%$ & 2.1 \\
Holotranscobalamin & $+0.9 \%(0.8-0.0 .9 \%)$ & $2.90 \%$ & 2.8 \\
Calcium & $+0.9 \%(0.8-0.9 \%)$ & $10.50 \%$ & 1.5 \\
Magnesium & $+0.3 \%(0.3-0.4 \%)$ & $2.20 \%$ & 1.9 \\
Iron & $+0.3 \%(0.3-0.4 \%)$ & $4.00 \%$ & 1.5 \\
Transferrin & $+0.3 \%(0.3-0.3 \%)$ & $1.70 \%$ & 2.1 \\
Other trace elements & $+0.2 \%(0.2-0.2 \%)$ & $0.70 \%$ & 2.4 \\
Homocysteine & $+0.1 \%(0.1-0.1 \%)$ & $0.40 \%$ & 1.7 \\
Other vitamins & $+0.1 \%(0.1-0.1 \%)$ & $0.50 \%$ & 2.4 \\
Methylmalonic acid & $+0.0 \%(-0.01-0.03 \%)$ & $0.01 \%$ & 10.0 \\
\hline
\end{tabular}

D 20.4\% (15.9\% performed once; $4.5 \%$ performed twice or more) and vitamin B12 17.6 (14.3\% performed once; $3.3 \%$ performed twice or more). Table 5 shows more detail about the number MLT by individual test.

\section{Discussion}

In this study, we explored population wide trends in MLT in Switzerland during 2012 to 2018 . We found an increase in all individual MLT but especially so in testing for vitamins where the proportion of tested persons doubled within seven years. Most eminently, the population tested for vitamin $\mathrm{D}$ tripled and the population tested for vitamin B12 doubled. The population tested for ferritin only increased by a factor of 1.5 but ferritin was the most prevalent test, ordered at least once in every fourth person

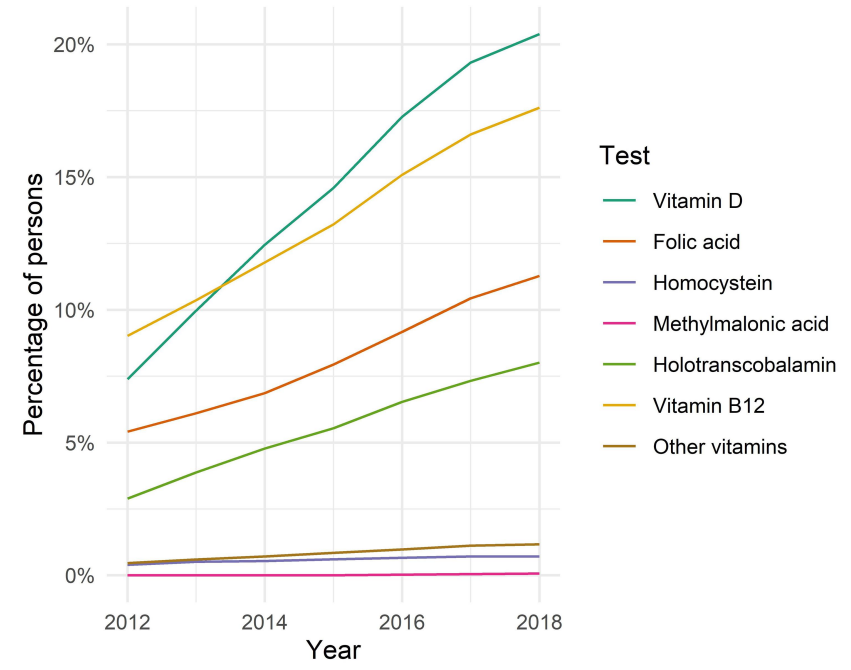

Figure I Temporal use of vitamin tests (2012-2018). in 2018. In addition, we explored incidence of MLT and frequency in 2018 and found that testing was also very common in the young population and that ferritin, vitamin $\mathrm{D}$ and vitamin B12 were performed more than once in over $7 \%, 4 \%$ and $3 \%$ of the population. Our results show that MLT are performed in a broad segment of the Swiss population and with high frequency in large number of cases.

We found that MLT are performed in an annually increasing proportion of the adult Swiss population: while a quarter of the population received any MLT in 2012, in 2018 already a third received an MLT. Among the individual MLT we observed strongest absolute increases in testing for vitamin D, vitamin B12 and ferritin: Vitamin D testing was performed in $7 \%$ of the population in 2012 and in $20 \%$ in

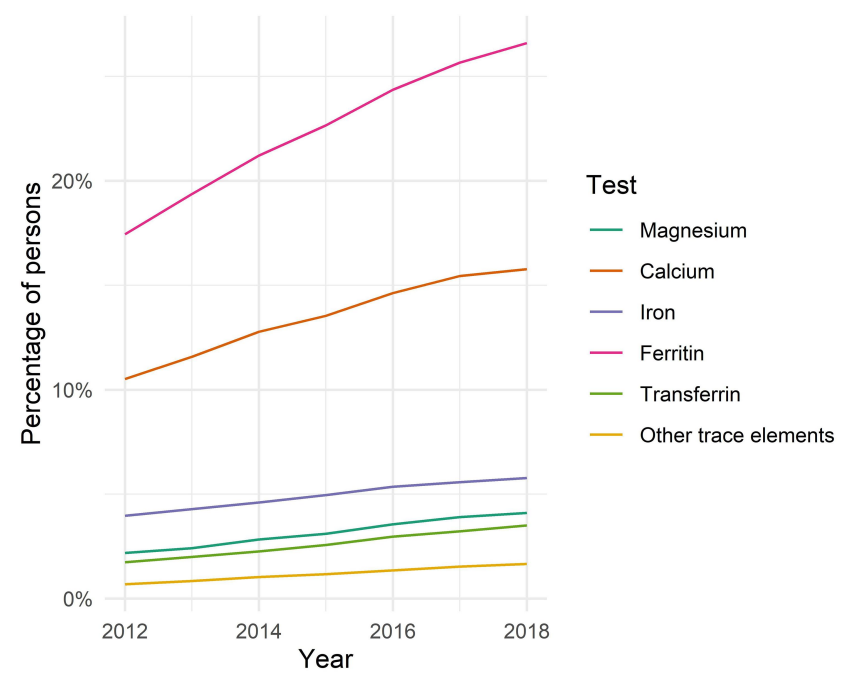

Figure 2 Temporal use of mineral and trace elements tests (2012-2018). 
Table 3 Sociodemographic Characteristics of the Study Sample from 2018

\begin{tabular}{|c|c|c|c|}
\hline \multirow[t]{2}{*}{ Variables } & With MLT & Without MLT & \multirow[t]{2}{*}{ P-value } \\
\hline & N (\%) & N (\%) & \\
\hline Total & 327320 (100.0\%) & 607365 (100.0\%) & \\
\hline Gender & & & $<0.001$ \\
\hline Female & 213200 (65.1\%) & 276425 (45.5\%) & \\
\hline Male & II4 I 20 (34.9\%) & 330940 (54.5\%) & \\
\hline Mean age $( \pm S D)$ & $57.1(19.5)$ & $48.6(19.1)$ & $<0.001$ \\
\hline Age in groups (years) & & & $<0.001$ \\
\hline $18-24$ & $20,3 \mid 3(6.2 \%)$ & 7I,409 (II.8\%) & \\
\hline $25-34$ & 34,057 (10.4\%) & $100,268(16.5 \%)$ & \\
\hline $35-44$ & 40,516 (I2.4\%) & $103,896(17.1 \%)$ & \\
\hline $45-54$ & 48,269 (14.7\%) & 105,467 (17.4\%) & \\
\hline $55-64$ & 52,072 (I5.9\%) & 90,202 (14.9\%) & \\
\hline $65-74$ & 57,891 (I7.7\%) & 67,124 (11.1\%) & \\
\hline $75-84$ & 50,645 (15.5\%) & 43,855 (7.2\%) & \\
\hline$\geq 85$ & 23,557 (7.2\%) & $25,144(4.1 \%)$ & \\
\hline Language region & & & $<0.001$ \\
\hline German & 232671 (7I.I\%) & 463,127 (76.3\%) & \\
\hline French & $66,217(20.2 \%)$ & 110,063 (18.1\%) & \\
\hline Italian & $28,432(8.7 \%)$ & 34,175 (5.6\%) & \\
\hline
\end{tabular}

Table 4 Incidence of MLT by Age Group in 2018

\begin{tabular}{|l|l|l|l|}
\hline \multirow{2}{*}{ Tests } & \multicolumn{3}{|l|}{ Age Group (years) } \\
\cline { 2 - 4 } & $\mathbf{1 8 - 4 4}$ & $\mathbf{4 5 - 6 4}$ & $\geq 65$ \\
\cline { 2 - 4 } & $\mathbf{N}(\%)$ & $\mathbf{N}(\%)$ & $\mathbf{N}(\%)$ \\
\hline Vitamins (all) & $63,341(17.1 \%)$ & $77,380(26.1 \%)$ & $106,099(39.6 \%)$ \\
Vitamin D & $48,887(13.2 \%)$ & $61,948(20.9 \%)$ & $79,753(29.7 \%)$ \\
Folic acid & $26,219(7.1 \%)$ & $31,637(10.7 \%)$ & $47,546(17.7 \%)$ \\
Homocysteine & $1708(0.5 \%)$ & $2530(0.9 \%)$ & $2427(0.9 \%)$ \\
Methylmalonic acid & $175(0.0 \%)$ & $196(0.1 \%)$ & $237(0.1 \%)$ \\
Holotranscobalamin & $18,360(5.0 \%)$ & $23,363(7.9 \%)$ & $33,171(12.4 \%)$ \\
Vitamin BI2 & $41,880(11.3 \%)$ & $50,922(17.2 \%)$ & $71,863(26.8 \%)$ \\
Other vitamins & $3967(1.1 \%)$ & $4210(1.4 \%)$ & $2722(1.0 \%)$ \\
Minerals (all) & $34,343(9.3 \%)$ & $49,280(16.6 \%)$ & $69,770(26.0 \%)$ \\
Magnesium & $10,055(2.7 \%)$ & $13,086(4.4 \%)$ & $15,178(5.7 \%)$ \\
Calcium & $32,439(8.8 \%)$ & $47,289(16.0 \%)$ & $67,681(25.2 \%)$ \\
Trace elements (all) & $82,007(22.1 \%)$ & $76,712(25.9 \%)$ & $92,653(34.5 \%)$ \\
Iron & $16,166(4.4 \%)$ & $17,647(6.0 \%)$ & $20,146(7.5 \%)$ \\
Ferritin & $81,316(22.0 \%)$ & $75,753(25.6 \%)$ & $91,551(34.1 \%)$ \\
Transferrin & $9434(2.5 \%)$ & $10,589(3.6 \%)$ & $12,673(4.7 \%)$ \\
Other trace elements & $6074(1.6 \%)$ & $5845(2.0 \%)$ & $3567(1.3 \%)$ \\
\hline
\end{tabular}

2018 and was thereby both frequently performed and subject to a large absolute and relative increase. Regarding testing for vitamin B12, we also found both a high testing frequency and in addition a strong temporal increase. Moreover, ferritin was also among the MLT that were frequently performed and increasing over time. Together, tests of vitamin $\mathrm{D}$, vitamin B12 and ferritin represent more than half of the MLTs performed but it is noteworthy that significant temporal increases occurred also in every other observed MLT without exception. Several studies so far found that laboratory testing is generally increasing and especially so for vitamin laboratory test. ${ }^{2-4,11}$ While this obviously reflects a global phenomenon also occurring in Switzerland, the observation remains still largely unexplained and paradox since we are unaware of a nutritional deficiency crisis in Switzerland, as in all the other countries where this trend has been observed. To find the highest incidence among MLT for ferritin testing is consistent with iron deficiency being the most common nutritional disorder also in industrialized countries. ${ }^{15,16}$ However, population based screening for iron deficiency is not recommended by eminent international guidelines such as the US Preventive Services Task Force (USPSTF), not even in the subgroup of pregnant women. ${ }^{17}$ Similarly, in the general population, screening for vitamin D deficiency is discouraged by the USPSTF and recommendations for screening for vitamin B12 deficiency are lacking entirely. ${ }^{10}$ In contrast, we found that in 2018 at least $27 \%, 20 \%$ and $18 \%$ of the entire Swiss population received at least one ferritin, vitamin D or vitamin B12 respectively. Such a high testing coverage resembles a de-facto population based screening which is not supported also by local guidelines and can be criticized at least for low value care or even overtesting. While our data was insufficient to advance the understanding of reasons for the high testing incidence or appropriateness in individual cases, several recent studies suggests that rates of inappropriate laboratory testing has increased considerably especially involving MLT. ${ }^{2,5,18-20}$ One possible explanation for the high testing rates could be that physicians have financial incentives for testing in the Swiss healthcare system, which may influence the testing rates. ${ }^{21}$

The finding that the population $\geq 65$ has the highest testing incidence is consistent with expectations since it represents the population segment at highest risk for micronutrient deficiencies. ${ }^{22,23}$ There is little external reference available for contrasting these results but a recent study of vitamin D testing incidence in the UK found that vitamin D testing incidence was $1.6 \%$ in 2015 which was already questioned of appropriateness. ${ }^{24}$ Our results of a testing incidence for vitamin D of $20 \%$ is more than ten times higher than that therefore even more questionable for appropriateness, especially in persons 18-44 years old. 
Table 5 Frequency of MLT in 2018

\begin{tabular}{|l|l|l|l|l|}
\hline \multirow{2}{*}{ Test } & \multicolumn{2}{l|}{ Number of Tests } & \multicolumn{2}{l|}{} \\
\cline { 2 - 5 } & $\mathbf{0}$ & $\mathbf{I}$ & $\mathbf{2}$ \\
\cline { 2 - 5 } & $\mathbf{N}(\%)$ & $\mathbf{N}(\%)$ & $\mathbf{N}(\%)$ & $\mathbf{N}(\%)$ \\
\hline Ferritin & $686,065(73.4 \%)$ & $180,923(19.4 \%)$ & $32,332(5.0 \%)$ & $21,365(2.3 \%)$ \\
Vitamin D & $744,097(79.6 \%)$ & $148,388(15.9 \%)$ & $24,667(2.6 \%)$ & $10,081(1.1 \%)$ \\
Vitamin BI2 & $770,020(82.4 \%)$ & $133,386(14.3 \%)$ & $23,694(2.5 \%)$ & $6612(0.7 \%)$ \\
Calcium & $787,276(84.2 \%)$ & $106,131(11.4 \%)$ & $13,924(1.5 \%)$ & $17,584(1.9 \%)$ \\
Folic acid & $829,283(88.7 \%)$ & $87,727(9.4 \%)$ & $8523(0.9 \%)$ & $3751(0.4 \%)$ \\
Holotranscobalamin & $859,791(92.0 \%)$ & $64,512(6.9 \%)$ & $7977(0.9 \%)$ & $1859(0.2 \%)$ \\
Iron & $880,726(94.2 \%)$ & $42,935(4.6 \%)$ & $4982(0.5 \%)$ & $3047(0.3 \%)$ \\
Magnesium & $896,366(95.9 \%)$ & $30,183(3.2 \%)$ & $4801(0.5 \%)$ & $3154(0.3 \%)$ \\
Transferrin & $901,989(96.5 \%)$ & $26,029(2.8 \%)$ & $4097(0.4 \%)$ & $1866(0.2 \%)$ \\
Other trace elements & $919,199(98.3 \%)$ & $9789(1.0 \%)$ & $2726(0.3 \%)$ & $1600(0.2 \%)$ \\
Other vitamins & $923,786(98.8 \%)$ & $4285(0.5 \%)$ & $697(0.1 \%)$ & $3888(0.4 \%)$ \\
Homocysteine & $928,020(99.3 \%)$ & $5799(0.6 \%)$ & $11(0.0 \%)$ & $169(0.0 \%)$ \\
Methylmalonic acid & $934,077(99.9 \%)$ & $597(0.1 \%)$ & $0(0.0 \%)$ \\
\hline
\end{tabular}

The incidence we calculated disregarded multiple annual tests in individual patients. Therefore, we investigated the frequency of specific tests per person. The MLT with the highest rate of being performed multiple times in individual persons was ferritin. Given the need for monitoring iron levels in patients requiring iron supplementation, a comparably high testing frequency seems understandable. However, the observation that more than seven percent of the entire Swiss population still received two or more ferritin tests in 2018 argues for a very high testing frequency which is possibly related to the easy access and reimbursement of advanced iron supplementation treatments in Switzerland. ${ }^{25,26}$ Vitamin D was in second place and vitamin B12 third place of MLT performed with high frequency, being tested twice or more in $4 \%$ and $3 \%$ of the Swiss population respectively in 2018. Repeated testing of these vitamins within one year is rather inexplicable since once detected, these vitamin deficiencies can usually be safely treated without the need for re-assessment. Therefore, these repeated MLT tests are especially suspect for potential overtesting. Calcium tests were performed twice or more in $4 \%$ of the population but since calcium requires closer monitoring in some patients (depending on comorbidities and medications) these repeat tests may be clinically appropriate in many cases.

\section{Strengths and Limitations}

The main strengths of this study are: First, the populationbased approach including more than six million person years and almost one million persons in 2018 (more than 10\% of the entire population). Second, the completeness of the data (covering all healthcare invoices from inpatient and outpatient setting). Third, the representativeness of the database. ${ }^{12,13}$ Fourth, the comprehensiveness focusing on a large set of MLT rather than a single laboratory test. Limitation of the study includes the potential for underreporting of claims (approximately 3\% according to internal Helsana analyses are underreported and are paid out-ofpocket). Thus, there is a potential underestimation of MLT in our data and actual MLT may be even more frequent than estimated by our study. However, our study still represents MLT payed for within the insurance system and thereby the part that is of greatest public concern. Second, since our data did not include clinical parameters (laboratory values) and diagnoses (eg for osteoporosis or anemia) we were unable to determine the actual appropriateness of MLT.

\section{Implications for Research}

The very high frequency of MLT and the strong temporal trends strongly indicate a need for further investigations since such potentially inappropriate testing may be responsible for substantial avoidable expenditures. Future research should therefore first precisely identify inappropriate use of MLT, and secondly targeted interventions should be tested to reduce inappropriate use of MLT. Among such possible interventions are campaigns such as "choosing wisely" or "smarter medicine" that focus on recommendations on interventions to avoid. ${ }^{9,27}$ 


\section{Implications for Practice}

For physicians, the results of our study suggest the need for reflecting current use of MLT and possibly reducing unnecessary tests. Guideline authors and opinion leaders could bring up the topic amongst physicians and public campaigns could inform the general population about the actual value and limitations of MLT.

\section{Conclusion}

In conclusion, the present study shows a high incidence and a strong increase in MLT in Switzerland and raises concerns about potential inappropriateness.

\section{Ethics Statement}

All data were retrospective, pre-existing, deidentified and anonymized in compliance with Swiss regulations on privacy law. Since the data used were retrospective, deidentified and anonymized health-related data prior to analysis, this study is not subject to the Swiss Federal Law on human research (Humanforschungsgesetz) and was thus exempted from the local ethics committee approval (ethical committee of the Canton Zurich) and from seeking informed consent of patients. ${ }^{28}$

\section{Author Contributions}

All authors made substantial contributions to conception and design, acquisition of data, or analysis and interpretation of data; took part in drafting the article or revising it critically for important intellectual content; agreed to submit to the current journal; gave final approval of the version to be published; and agree to be accountable for all aspects of the work.

\section{Funding}

This research received no external funding.

\section{Disclosure}

DrCarola A Huber is an employee of Helsana Group. Dr Eva Blozik is an employee of Helsana Group and reports grants from Swiss Cancer Research Foundation, Novartis Pharma, Vifor Pharma, and MSD Switzerland, outside the submitted work. Mr Markus Näpflin is an employee of Helsana Group and reports grantsfrom Novartis Pharma Switzerland, MSD, Amgen, and Vifor, outside the submitted work. The authors declare no other conflicts of interest in this work.

\section{References}

1. Forsman RW. Why is the laboratory an afterthought for managed care organizations? Clin Chem. 1996;42(5):813-816. doi:10.1093/clinchem/42.5.813

2. O'Sullivan JW, Stevens S, Hobbs FDR, et al. Temporal trends in use of tests in UK primary care, 2000-15: retrospective analysis of 250 million tests. BMJ. 2018;363:k4666. doi:10.1136/bmj.k4666

3. Naugler C. A perspective on laboratory utilization management from Canada. Clinica Chimica Acta. 2014;427:142-144. doi:10.1016/j. cca.2013.09.022

4. Mindemark M, Larsson A. Longitudinal trends in laboratory test utilization at a large tertiary care university hospital in Sweden. Ups J Med Sci. 2011;116:34-38.

5. Bilinski K, Boyages S. Evidence of overtesting for vitamin D in Australia: an analysis of 4.5 years of Medicare Benefits Schedule (MBS) data. BMJ Open. 2013;3(6):e002955. doi:10.1136/bmjopen2013-002955

6. Caillet P, Goyer-Joos A, Viprey M, Schott AM. Increase of vitamin D assays prescriptions and associated factors: a population-based cohort study. Sci Rep. 2017;7:1-7.

7. Rodd C, Sokoro A, Lix LM, et al. Increased rates of 25-hydroxy vitamin D testing: dissecting a modern epidemic. Clin Biochem. 2018;59:56-61. doi:10.1016/j.clinbiochem.2018.07.005

8. Gonzalez-Chica D, Stocks N. Changes to the frequency and appropriateness of vitamin D testing after the introduction of new Medicare criteria for rebates in Australian general practice: evidence from 1.5 million patients in the NPS MedicineInsight database. BMJ Open. 2019;9(3):e024797. doi:10.1136/bmjopen-2018-024797

9. Choosing Wisely: Vitamin D Tests. When you need them-and when you don't. Available online: https:/www.choosingwisely.org/patientresources/vitamin-d-tests/. Accessed 9 March 2020.

10. Lefevre ML. Screening for Vitamin D Deficiency in Adults: U.S. Preventive Services Task Force Recommendation Statement. Ann Intern Med. 2015;162(2):133-140. doi:10.7326/M14-2450

11. Schumacher LD, Jäger L, Meier R, et al. Trends and between-Physician Variation in Laboratory Testing: A Retrospective Longitudinal Study in General Practice. J Clin Med. 2020;9(6):1787. doi:10.3390/jcm9061787

12. Huber CA, Schwenkglenks M, Rapold R, Reich O. Epidemiology and costs of diabetes mellitus in Switzerland: an analysis of health care claims data, 2006 and 2011. BMC Endocr Disord. 2014;14 (1):44. doi:10.1186/1472-6823-14-44

13. Haller E, Watzke B, Blozik E, et al. Antidepressant prescription practice and related factors in Switzerland: A cross-sectional analysis of health claims data. BMC Psychiatry. 2019;19(1):196. doi:10.1186/ s12888-019-2178-4

14. Federal Office of Public Health. List of analyses with tariff. Available online: https://www.bag.admin.ch/bag/de/home/versicherungen/kran kenversicherung/krankenversicherung-leistungen-tarife /Analysenliste.html. Accessed 3 March 2020.

15. United Nations Children's Fund, United Nations University, World Health Organization. Iron Deficiency Anaemia - Assessment, Prevention and Control. WHO/NHD/01.3. Geneva: World Health Organization; 2005.

16. World Health Organization, Centers for Disease Control and Prevention. Assessing the Iron Status of Populations. 2nd ed. Geneva: World Health Organization; 2007.

17. Siu AL. Screening for Iron Deficiency Anemia and Iron Supplementation in Pregnant Women to Improve Maternal Health and Birth Outcomes: U.S. Preventive Services Task Force Recommendation Statement. Ann Intern Med. 2015;163 (7):529-536. doi:10.7326/M15-1707

18. Chami N, Simons JE, Sweetman A, Don-Wauchope AC. Rates of inappropriate laboratory test utilization in Ontario. Clin Biochem. 2017;50(15):822-827. doi:10.1016/j.clinbiochem.2017.05.004 
19. Watson J, Hamilton F, Bailey S, Mounce L, Hamilton W. Clinical implications of increased testing in primary care. $B M J$. 2019;264:175. doi:10.1136/bmj.1175

20. Isaac T, Rosenthal MB, Colla $\mathrm{CH}$ :, et al. Measuring overuse with electronic health records data. Am J Manag Care. 2018;24:19-25.

21. van Merode GG, Stroink AE, Maarse JA, Goldschmidt HM. Impact of insurance coverage type on laboratory test ordering behaviour of general practitioners. World Hosp Health Serv. 2000;36(7-12):36-37.

22. Nieuwenhuizen WF, Weenen H, Rigby P, Hetherington MM. Older adults and patients in need of nutritional support: review of current treatment options and factors influencing nutritional intake. Clin Nutr. 2010;29(2):160-169. doi:10.1016/j.clnu.2009.09.003

23. Franzke B, Schober-Halper B, Hofmann M, et al. Fat Soluble Vitamins in Institutionalized Elderly and the Effect of Exercise, Nutrition and Cognitive Training on Their Status-The Vienna Active Aging Study (VAAS): A Randomized Controlled Trial. Nutrients. 2019;11(6):1333. doi:10.3390/nu11061333

24. Crowe FL, Jolly K, MacArthur C, et al. Trends in the incidence of testing for vitamin $\mathrm{D}$ deficiency in primary care in the UK: a retrospective analysis of The Health Improvement Network (THIN), 2005-2015. BMJ Open. 2019;9(6):e028355. doi:10.1136/ bmjopen-2018-028355
25. Biétry FA, Hug B, Reich O, Susan JS, Meier CR. Iron supplementation in Switzerland-A bi-national, descriptive and observational study. Swiss Med Wkly. 2017;147:w14444.

26. Meier R, Keizer E, Rosemann T, Markun S. Indications and associated factors for prescribing intravenous iron supplementation in Swiss general practice: a retrospective observational study. Swiss Med Wkly. 2019;149:w20127.

27. Gaspoz JM. Smarter medicine: do physicians need political pressure to eliminate useless interventions? Swiss Med Wkly. 2015;145: w14125.

28. Federal Council. Federal act of 30 September 2011 on research involving human beings (human research act, HRA). Available online: https://www.admin.ch/opc/en/classified-compilation /20061313/index.html. Accessed 30 September 2020.

\section{Publish your work in this journal}

The International Journal of General Medicine is an international, peer-reviewed open-access journal that focuses on general and internal medicine, pathogenesis, epidemiology, diagnosis, monitoring and treatment protocols. The journal is characterized by the rapid reporting of reviews, original research and clinical studies across all disease areas. The manuscript management system is completely online and includes a very quick and fair peer-review system, which is all easy to use. Visit http://www.dovepress.com/ testimonials.php to read real quotes from published authors. 